\title{
Safety assessment of steel framework of a utility boiler
}

\author{
Bin $\mathrm{Xu}^{1}$ \& Enpin Liu ${ }^{1}$ \& Jingdong Wang ${ }^{1}$ \& Liangsheng Chen ${ }^{1}$ \\ ${ }^{1}$ No.399, North Nujiang Road,Shanghai,China
}

KEYWORD: safety assessment, steel framework, finite element analysis, seismic loads.

ABSTRACT: The steel framework of a utility boiler was an important structure sustained loads, and its strength and stiffness were primary factors in structural design. Stiffness was assessed by measuring perpendicularity of pillars. For this steel framewok seismic loads was significant to the entire strength. In order to refer to the influence of seismic loads, finite element method was adopted to analyze the strength of the whole steel framework. According to the results of finite element analysis, the maximum equivalent stress was $102.9 \mathrm{MPa}$, which could satisfy the strength requirement. It indicated that this steel framework could satisfy the requirement of practical working conditions.

\section{INTRODUCTION}

Steel framework is an important component of utility boiler. It was used to support and fix the body of boiler, so strength design of the steel framework had significant influence to the entire utility boiler, which could determine the entire safety of boiler. Therefore, a precise method of strength assessment was a key factor in structural design. In order to add denitrification process, some equipments were assembled in this steel structure. So this steel framework was modified by adding some pillars and beams. Consequently, the strength of this steel framework should be assessed again.

In the literature, many scholars had made some valuable research on steel structures of boilers. Xiao [1] used ANSYS to analyze spatial static peculiarity of boiler steel structure, main girder, connection of main girder with column and the overall stability, only the dead loads, live loads, wind loads and their combination were considered, but seismic load was not referred. Dai [2] proposed a reconstruction and enforcement method according to the dynamic analysis involving dead loads, live loads, wind loads and seismic loads. Liu [3] analyze the spatial static peculiarity, dynamic response and the whole stability of the boiler steel structure. Wang [4] analyzed the strength design of steel connection in denitration transformation for power plants. Yue [5] and Cheng [6] introduced the calculating method of seismic loads and wind loads respectively. Zhang [7] introduced the behavior analysis and optimum design for the steel plate girders in power plants. $\mathrm{Wu}[8]$ used finite element method to analyze the structure of the transformation plan and security anlysis. Although these researches had made great progress on structural analysis of boiler steel structure, these virtual models were limited to two dimensions, and the analysis results were not precise and should be improved by expanding the model to three dimensions.

A 3D finite element model was advanced to assess the strength of steel framework of boiler, and seismic loads were referred in this research.

\section{Stiffness assessment}

The steel framework was composed of six pillars and many beams which were made of section steels. The total height of this steel framework was 37 meters. In order to verify the stiffness, the errors of perpendicularity of six pillars were measured by total positioning systems. The side view of this steel framework was as shown in Figure 1. The tested positions were marked by numbers in Figure 1. 


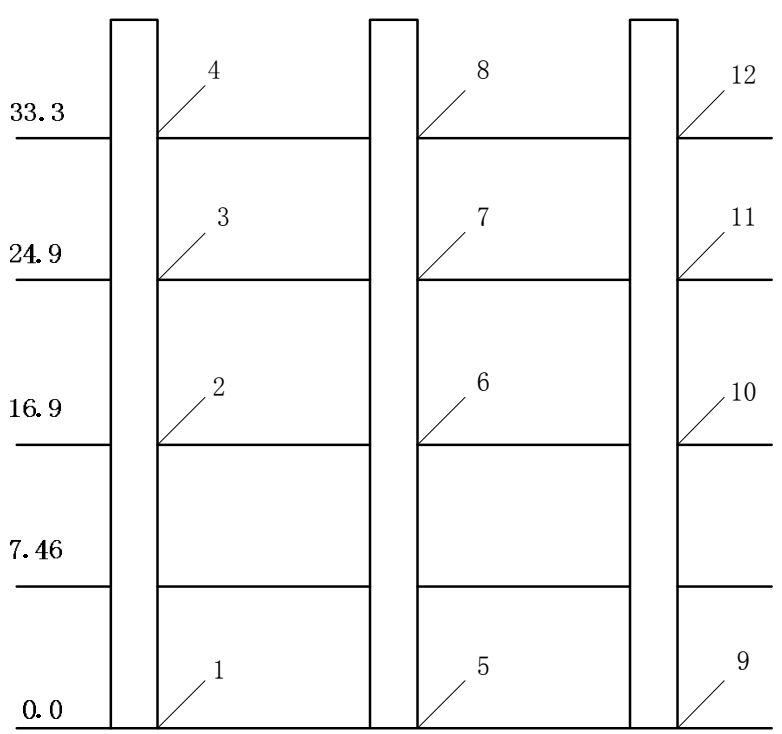

Fig. 1 side view of steel framework

The tested results were listed in Table 1.

Table 1 the maximum error of perpendicularity of pillars

The maximum error $\quad \mathrm{X}(\mathrm{mm})$

\begin{tabular}{ccc}
\hline Left & point 1-4 & 25 \\
Left & point 5-8 & 15 \\
Left & point 9-12 & 33 \\
Right & point 1-4 & 26 \\
Right & point 5-8 & 11 \\
Right & point 9-12 & 27
\end{tabular}

In Table $1, \mathrm{X}$ was the tested direction in the coordinate of total positioning system. As listed in Table 1, the maximum error of perpendicularity of pillars was $33 \mathrm{~mm}$, which could satisfy the requirement of standards of boiler steel structures.

\section{Finite element analysis}

According to the drawings of reconstruction, A three dimensional model of the steel framework was built as shown in Figure 2. The loads of top plate of this boiler were 1352t, which included their gravity. The live loads of running layer could be imposed on the node of $8 \mathrm{~m}$ and calculated by $10 \mathrm{KN} / \mathrm{m} 2$. The gravity of other equipments was also considered, so the total dead loads were $2260 \mathrm{t}$ and the total live loads were 340t. Wind loads could be neglected since this steel framework located indoors.

Seismic loads were important to the strength of this steel framework. Referenced to standards of boiler steel structures, the aseismatic degree was defined as 7 . According to the standards of steel structures, the peak value of ground shocking acceleration was $0.1 \mathrm{~g}$, and the coefficient of horizontal response was defined as 0.08 . The damp ratio was equal to 0.035 , and the coefficient of seismic loads influencing on top plane of the pillars was defined as 0.0482 . 


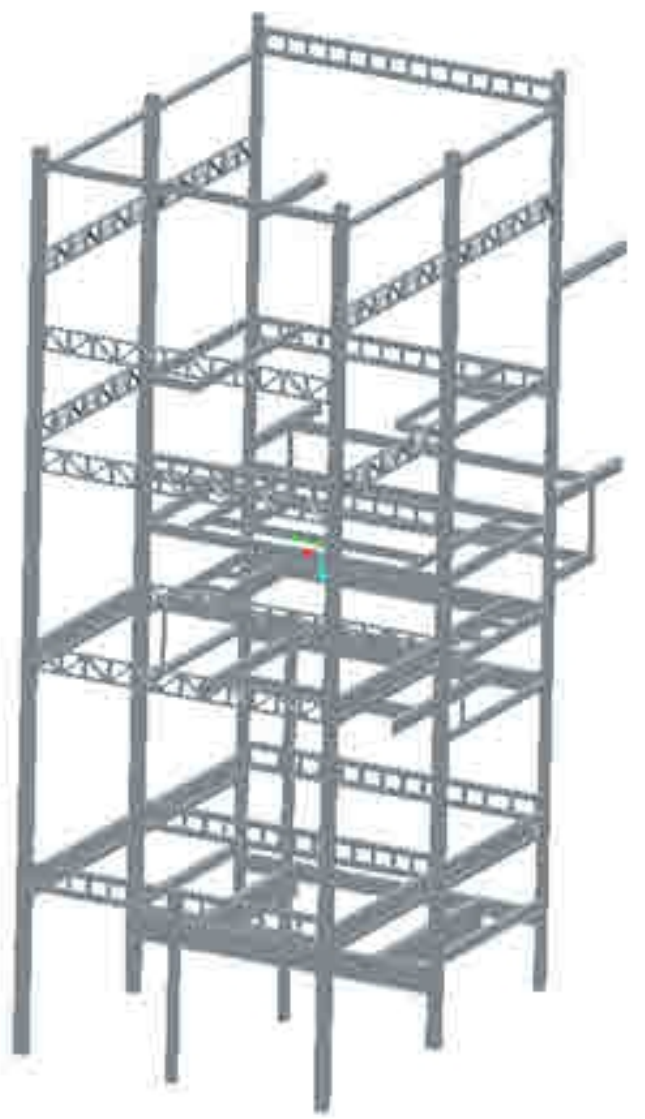

Figure 2 the three dimensional model of the steel framework

According to statistics of loads above mentioned, the seismic loads were $17 \mathrm{t}$ which should be imposed on the simulating models and the seismic loads were 11.2t imposed on the top plane.

In order to increase the simulating precision, solid elements were adopted to build a 3D finite element model; moreover sweep method and refining method were adopted too. The 3D finite element model was illustrated in Figure 3. 


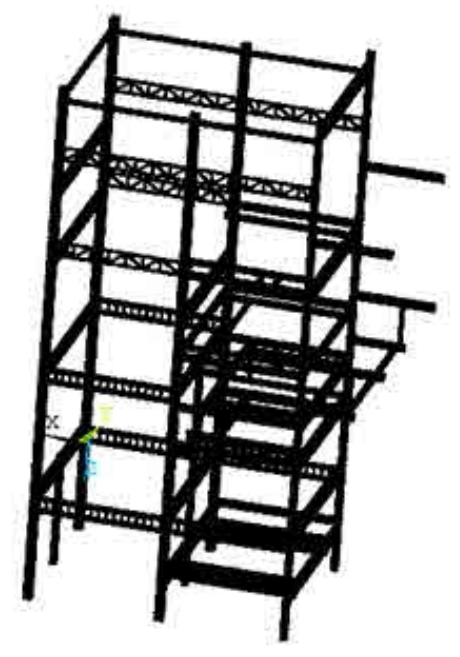

(a)

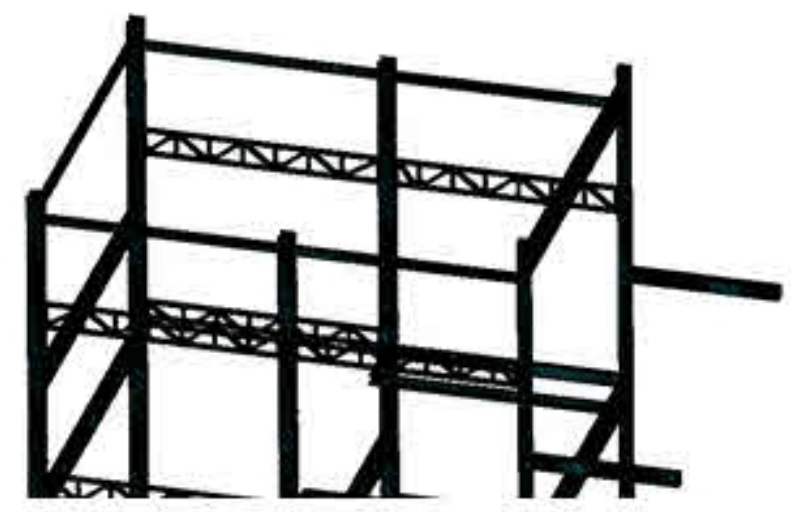

(b)
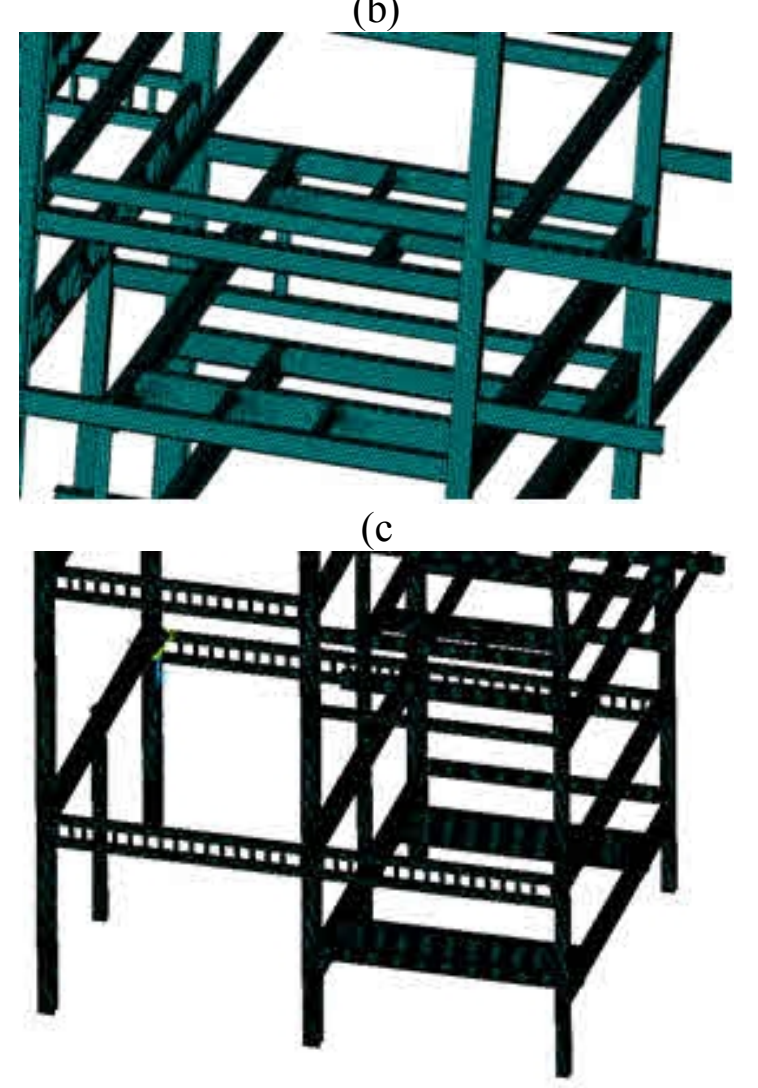

(d)

Fig 3 finite element model of the steel framework 


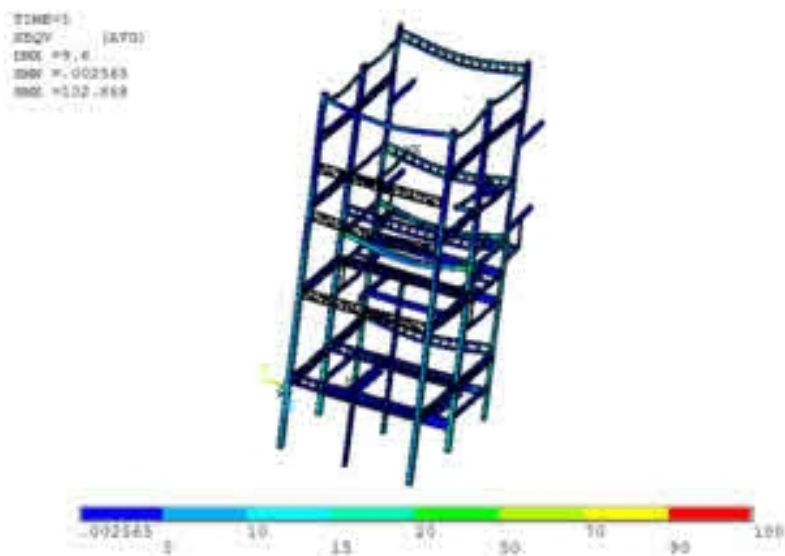

(a)

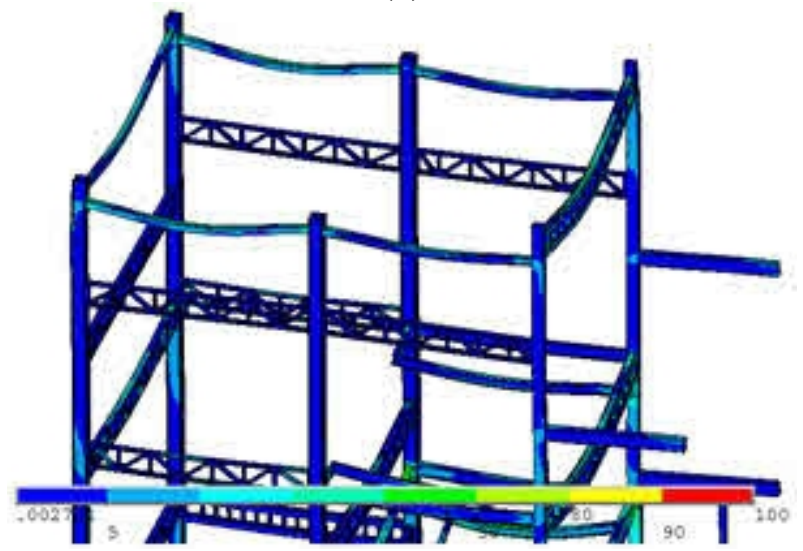

(b)

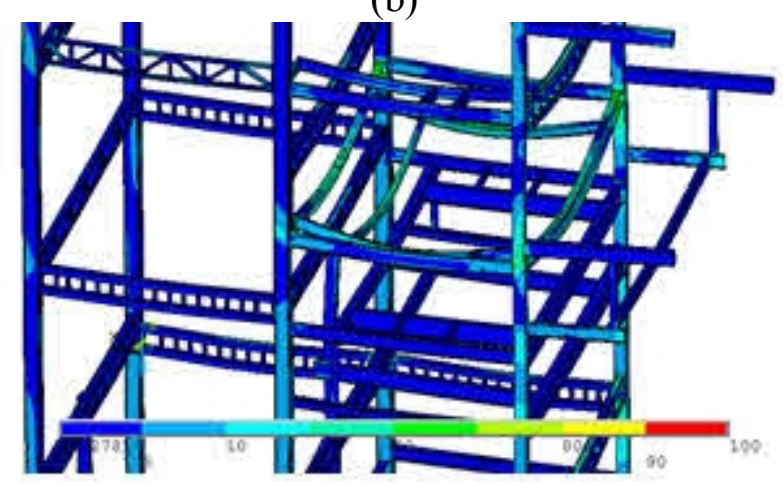

(c)

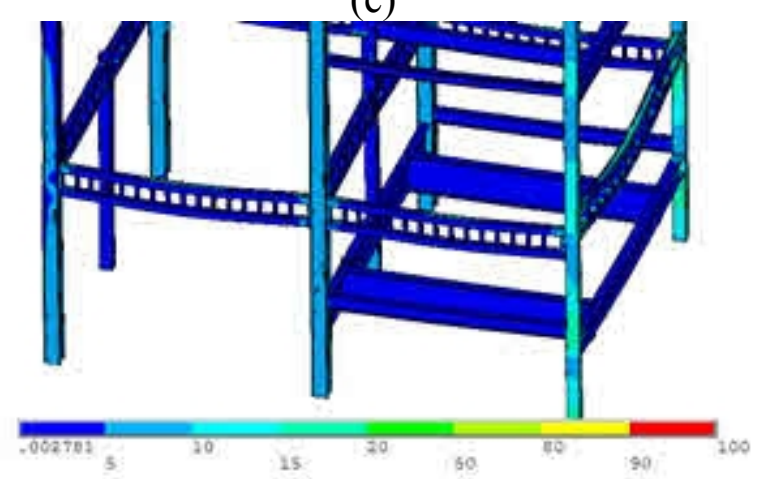

(d)

Fig 4 the entire contour of Von Mises stress of the steel framework

Static analysis was executed by finite element software. The entire contour of Von Mises stress of the steel framework was shown in Figure 4. As shown in Figure 4, the maximum value of Von Mises stress was $102.9 \mathrm{MPa}$, and the maximum deflection was $9.6 \mathrm{~mm}$. Since the material of these 
steel framework was Q235 steel, the strength of this structure could satisfy the strength requirement of materials.

\section{Conclusion}

Based on the perpendicularity measurement, it indicated that some errors of perpendicularity existed in these pillars, but they could satisfy the requirement of standards of boiler steel structures. According a precise finite element analysis, this steel framework could satisfy the strength requirement of materials under current working cases.

\section{References}

[1].Xiao Bin. Static and stability analysis for boiler steel structure of power plant [D]. Master dissertation of Shanghai Jiaotong University, 2008.

[2].Dai Qingsheng. Reliability analysis of reconstruction and enforcement on power station boiler steel frame [D]. Master dissertation of Wuhan University of Science and Technology, 2003.

[3] Liu Xiaoqin. The whole stability research of boiler steel structure [D]. Master dissertation of Wuhan University of Science and Technology, 2006.

[4] Wang Yuanqing, Luo Ruiqi, Zhang Tianshen etc. Analysis of steel connection strengthening design in denitration transformation for power plants [J]. Sichuan buildin science, vol.40 No.4,2014. P.77-82.

[5] Yue Xue, Lou Dekui, Zhang Benfu. Research on calculating method of seismic loads of utility boilers [J]. Power system engineering. Vol 16 No. 1,2000, P.24-25.

[6] Cheng Dongmei, Chen Ming, Qiao Hongbin etc. Wind load calculation and analysis of a foreign-related boiler steel structure [J]. Journal of engineering for thermal energy and power. Vol 25 No. 1,2010, P.61-64.

[7]. Wenyuan Zhang, Xianguo Meng. Behavior analysis and optimum design for the steel plate girders in power plant [J]. Steel structures. 2012. P.676-681.

[8]Wu Jingtao, Zheng Jianhua, Ning Tao. Security analysis for desulfurization and denitrification transformation of one power plant steel structure [C]. National conference of buiding identification and disease dealing, 2014. P.33-37. 